DOI: $10.24850 /$ j-tyca-2019-04-04

Special Article

\title{
Rationality Analysis of the Heihe River '97' Water Diversion Scheme under Changing Environment
} Análisis de racionalidad del esquema '97' de desviación del agua del río Heihe bajo un entorno cambiante
M. Zhao ${ }^{1}$
X. Jiang ${ }^{2 *}$
Q. Huang ${ }^{3}$
G. Dong ${ }^{4}$

${ }^{1}$ State Key Laboratory Base of Eco-Hydraulic Engineering in Arid Area, Xi'an University of Technology, Shaanxi, China, email: mlzhao1314@outlook.com, ORCID 0000-0003-0474-2637

${ }^{2}$ Northwest University, Shaanxi, China, email: xhjiang@nwu.edu.cn, ORCID 0000-0002-3805-5766

${ }^{3}$ State Key Laboratory Base of Eco-Hydraulic Engineering in Arid Area, Xi'an University of Technology, Shaanxi, China, email: syhuangqiang@163.com, ORCID 0000-0001-9183-9298

${ }^{4}$ Institute of Hydraulic Research, YRCC, Henan, China, email: dongguotao@hky.yrcc.gov.cn, ORCID 0000-0002-1292-2091

*Corresponding author: Xiaohui Jiang, email: xhjiang@nwu.edu.cn

\section{Abstract}

The environmental condition has changed after the implementation of the ' 97 ' water diversion scheme, and there are still queries regarding the rationality of the water diversion scheme due to the potential difficulty of completing the releasing goal of Zhengyixia section. This paper simulated the implementation of the scheme through a simulation model for water resources allocation in the Heihe River. Then, the rationality of the water diversion scheme was evaluated. Results indicated that, in the current water demand situation, the releasing indicator could not be completed. The releasing indicator could be accomplished under two returning farmland schemes in the midstream, but the irrigation guarantee rate is low and the groundwater is overused. 
Therefore, there are some irrationalities between the '97' water diversion scheme based on economic, social and hydrologic conditions in the Heihe River in the mid-1980s and the current situation of the Heihe River Basin.

Keywords: Rationality, changing environment, ecological restoration, the Heihe River, water resources allocation, '97' water diversion scheme.

Received

Accepted

\section{Introduction}

The Heihe River is the second largest inland river in China. In recent decades, the water demand in the middle reaches of the Heihe River had increased dramatically (Huang et al. 2016c) with the rapid regional development of the economy and society. This has resulted in a significant decrease in the releasing water to the lower reaches, vegetation degeneration and the disappearance of lakes. One of the most severe challenges is sustainable management due to a shortage of water resources (Kharrazi et al. 2016; Huang et al. 2016a; Huang et al. 2016b). To curb the trend of ecological degradation in the lower reaches of the Heihe River, the Yellow River Conservancy Commission of the Ministry of Water Resources has developed a water diversion scheme for the middle and lower reaches of the Heihe River in different inflow years. After implementing the scheme, the utilization efficiency of water resources has been improved dramatically, and the domestic, productive and ecological water in the basin has been allocated reasonably (Jiang \& Liu 2009; Tang \& Jiang 2009; Zhang et al. 2011; Zhao \& Huang 2015).

However, some increasingly severe problems about the water diversion scheme have been exposed. On the one hand, the middle reaches of the Heihe River faced critical water shortage constraints because of the intensive evapotranspiration, limited water inflow, minimal precipitation, and obligatory water discharge to downstream since 2000. As a result, the environment in the middle reaches has degenerated, and the restoration of the oasis in the lower reaches of the Heihe River has still not been reached (Jiang et al. 2009; Lu et al. 2011). On the other hand, under the demand of the '97' water diversion scheme, the releasing water of the Zhengyixia section is still not adequate. The 
inadequate scheme showed that the higher the inflow was, the more difficult it was to achieve the mission. The problem of inadequate releasing water of the Zhengyixia section has become a major concern (Liu \& Wang 2012; Wu et al. 2015). Gansu Province and Inner Mongolia Autonomous Region cannot reach an agreement on how to implement the '97' water diversion scheme. The economic and social conditions, as well as the hydrologic connectivity in the Heihe River, had changed significantly after the implementation of the water diversion scheme. Therefore, it is necessary to systematically analyze the implementation of the water diversion scheme through a quantitative manner under changing environment, and scientifically evaluate the rationality of the '97' water diversion scheme, thereby providing a solid basis for the scientific management of water resources in the Heihe River Basin.

\section{Study Area}

The Heihe River Basin covers the Inner Mongolia Autonomous Region, Qinghai and Gansu Provinces from upper reaches to lower reaches, whose area is about $134000 \mathrm{~km}^{2}$. The Heihe River is divided into three parts by Yingluoxia section and Zhengyixia section. Figure 1 shows the map of the Heihe River Basin. 


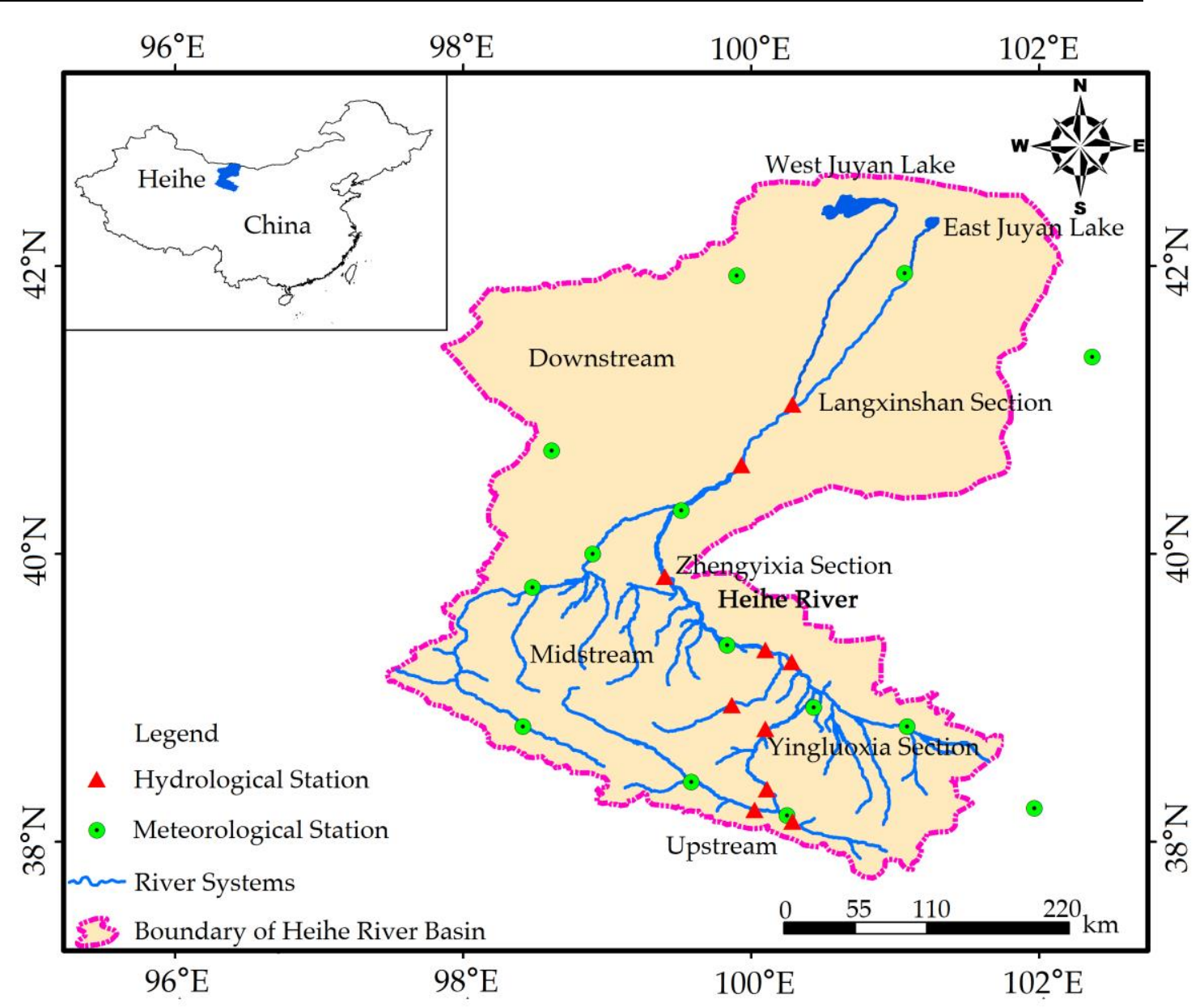

Figure 1. Map of the Heihe River Basin.

\section{Change after the Establishment of the Water Diversion Scheme}

The '97' water diversion scheme was made according to hydrological data and the economic and social conditions from 1955 to 1986. 


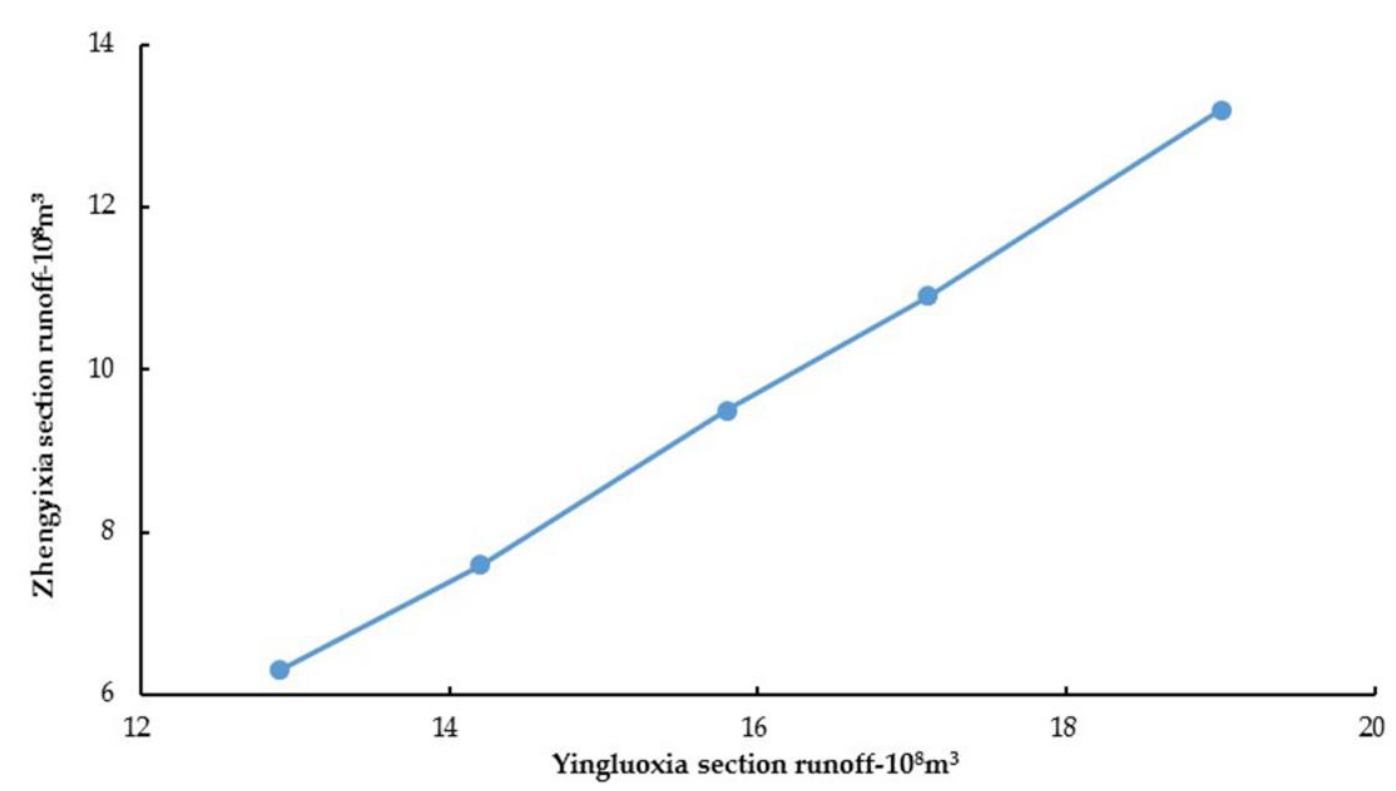

Figure 2. The ' 97 ' water diversion scheme.

Details of the '97' water diversion scheme are shown in Figure 2. The aim of the '97' water diversion scheme is to ensure water usage in the middle reaches in low flow years, and to allocate more water to the downstream in high flow years. The premise of implementing water diversion scheme is that water-saving irrigation measures should be adopted in the middle reaches, and the irrigation area could not expand anymore. However, the basic conditions have changed significantly since the establishment of the water diversion scheme.

The hydrologic connectivity in the middle reaches of the Heihe River has changed significantly after the establishment of the water diversion scheme. Because the irrigation area in the tributary was small in the 1950 s and 1960s, there was only one mountain reservoir, which supplied about 2-3 $\times 10^{8} \mathrm{~m}^{3}$ water to the mainstream. By the end of 1980 's, due to the sustained development of the irrigation, the reservoirs had increased to 19 , which only supplied about 0.7-0.9 $\times 10^{8}$ $\mathrm{m}^{3}$ water to the mainstream. By the end of 1990 's, there were 23 tributary reservoirs. The inflow of the tributaries was effectively retained and consumed. Many of the main streams and tributaries completely lost surface hydraulic connections, which fundamentally caused changes in the water resources conditions from the tributaries to the mainstream. The basic conditions of synchronization between the tributaries and the mainstream are not held anymore.

The economic and social conditions in the middle reaches of the Heihe River have changed greatly since the construction of the water diversion scheme. The agriculture and economy in Zhangye have developed fast since 1980-1990's. Through water consumption analysis 
in the mid-1980s and the end of 1990s, the population increased by 152.9 thousand, the cultivated land increased by $373.6 \mathrm{~km}^{2}$, and the agricultural water consumption increased by $2.21 \times 10^{8} \mathrm{~m}^{3}$. The annual water consumption was approximately $8.3 \times 10^{8} \mathrm{~m}^{3}$, whereas the available amount confirmed in the current water allocation scheme was only $6.3 \times 10^{8} \mathrm{~m}^{3}$.

The area of cultivated land in the middle and lower reaches of the Heihe River has increased greatly since the implementation of the ' 97 ' water diversion scheme. The cultivated land area in the middle reaches increased by $280 \mathrm{~km}^{2}$, and the water consumption exceeded approximately $2 \times 10^{8} \mathrm{~m}^{3}$. In Ejina $\mathrm{Qi}$, the cultivated land area increased by $60 \mathrm{~km}^{2}$, which caused more than $0.7 \times 10^{8} \mathrm{~m}^{3}$ of the water used for agricultural activities.

\section{Implementation of the '97' Water Diversion Scheme}

The water dispatching of the Heihe River improved the downstream environment by reducing the middle irrigation water usage and increasing the water volume to the downstream. According to the principle of "full-scale closed, centralized discharge" during the key scheduling period, the water diversion modes were roughly divided into three stages. First, from 2000 to 2003, the measures of "full-scale closed" were at the trial stage; the water diversion mode had not been fixed. Second, when water division moved into the mature stage in 2004 to 2007, measures of "full-scale closed, centralized discharge" were conducted in mid-July, mid-August and early September till the end of October every year. The time table had been substantially fixed, which achieved good effects. Finally, ecological water dispatching has been implemented since 2008. In order to adapt to the change in the planting structure in the midstream and the ecological water requirement in the downstream, the time of closed spring scheduling was extended, which improved the water discharged in the spring of the Zhengyixia section. Satisfactory results have been achieved since the water division was implemented, and the total actual amount of discharged water in the Zhengyixia section was $132.04 \times 10^{8} \mathrm{~m}^{3}$ (annual average $10.16 \times 10^{8} \mathrm{~m}^{3}$ ), which has been increased significantly from the 1990 s.

According to the analysis of the runoff data from 2000 to 2015, the Zhengyixia section suffered a decrease of $24.3 \times 10^{8} \mathrm{~m}^{3}$ water volume annually and accounted for $10.9 \%$ of the water volume that should 
have been discharged. Compared with the annual target amount of the discharged water, the actual amount of discharged water of the Zhengyixia section was lower.

Since the water diversion scheme has been implemented, most of the years were high flow years. The rationality to different inflows of the scheme cannot be evaluated because the water diversion scheme has not been tested over a long period of time. The implementation of the scheme under the different water requirements from 1954 to 2012 was simulated by a simulation model for water resources allocation in the middle and lower reaches of the Heihe River, and the rationality of the water diversion scheme was evaluated.

\section{Methods}

Global methods for water resources allocation can be mainly divided into three categories: optimization, simulation and a combination of both (You et al. 2006; Thevs et al. 2014). Generally, the result of an optimization method can be obtained by establishing a mathematical model, setting the target and determining the constraints. However, due to the complexity of the water resources system, it is difficult to construct a complete model with the objective function and constraints; moreover, the model may be too complicated to solve or the optimization results do not correspond to the actual situation. The simulation model emphasizes the description of the details. Through the simulation and control of each process of the water resources system, water resources were allocated under the pre-set rules or constraints. Compared to the optimization model, the simulation model is more flexible and adaptable, and it is easier to combine the experience of professionals.

Considering the characteristics of complex transformation between surface water and groundwater and the allocation of water resources mainly under artificial control, the paper generalized the water resources system using abstraction and generalization methods and proposed a set of simulation processes that are controlled by rules. Then, the simulation model for the water resources allocation in the middle and lower reaches of the Heihe River was established through the process of object-oriented programming. 


\section{Construction of the Model}

The water resources system of the Heihe River Basin is a complex and complete system that consists of surface water and groundwater such as rivers, reservoirs and spring water. Therefore, the water transformation characteristics of the middle reaches of the Heihe River Basin and factors of water balance, such as the seepage of the river course, discharge of spring water, phreatic water evaporation and field infiltration of canal system, should be included in the water resources allocation model of the Heihe River to capture the water balance calculation under different scenarios of inflow and water consumption.

The water allocation models of the Heihe River mainstream mainly included a groundwater equilibrium model of the irrigation area in the middle reaches, a water resources balance model between supply and demand and a water resources allocation model. The groundwater equilibrium model was mainly used to calculate the groundwater replenishment under different water allocation schemes and releasing balances. The water resources balance model between supply and demand and the water resources allocation model were mainly used to analyze the water demand, supply and shortage in irrigation areas and to calculate the water resources. The framework of the water resources model is shown in Figure 3. 


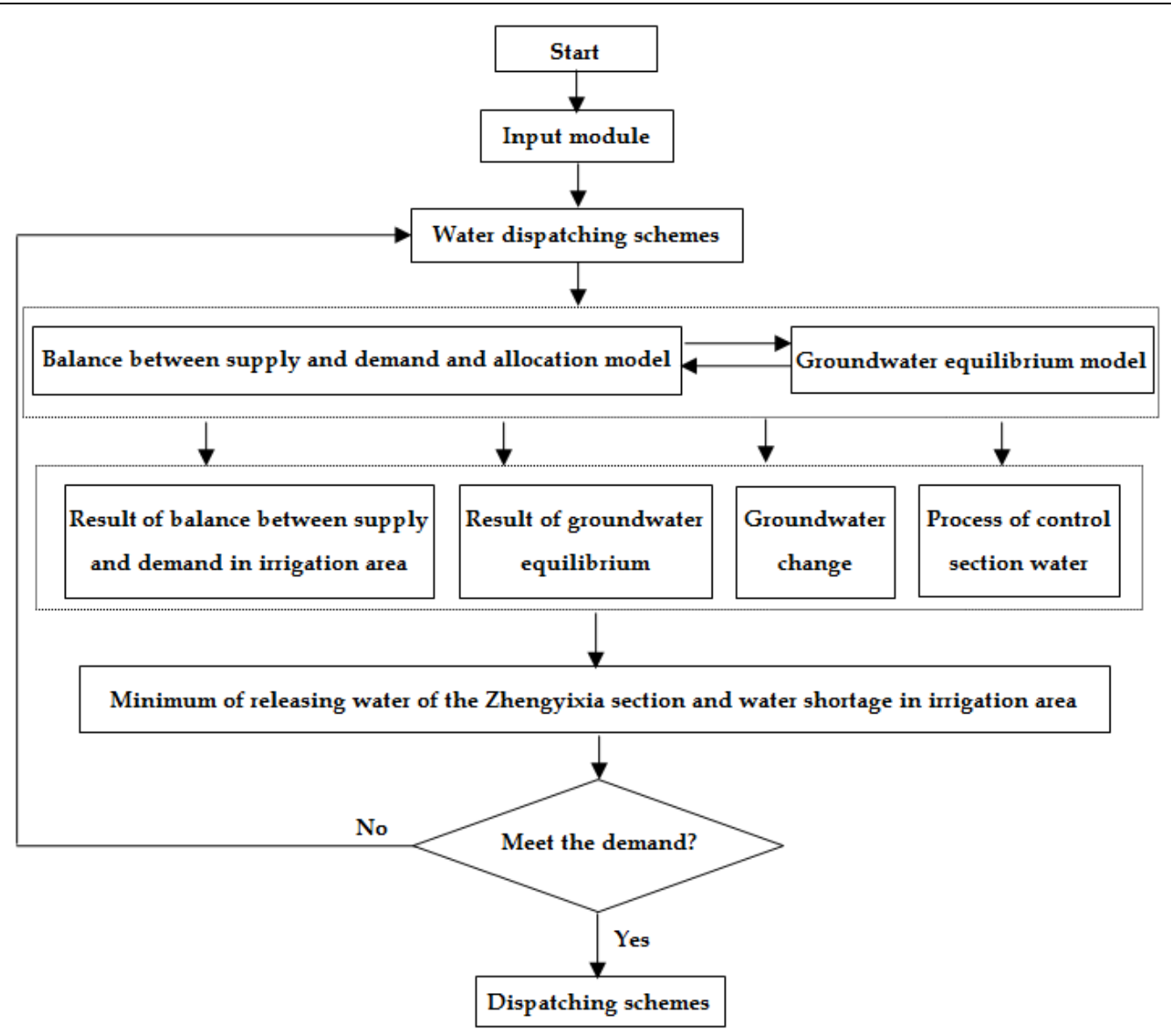

Figure 3. Frame of the water resources allocation model.

\section{Groundwater Equilibrium Model in the Middle Reaches of the Heihe River}

East of middle reaches of the Heihe River mainstream, the replenishment and drainage of groundwater were calculated using the scale of the irrigation unit. Replenishment comes from the aquifer of the calculated area of precipitation, surface water infiltration and groundwater runoff in per unit time under the conditions of a natural state or artificial exploitation, including Piedmont groundwater lateral replenishment, condensate rainfall infiltration replenishment, channel leakage replenishment, canal seepage replenishment, field infiltration, underground lateral runoff replenishment, and plain reservoir seepage replenishment. Based on the methods of drainage, the drainage was divided into potential water evaporation, groundwater exploitation, spring overflow, and underground lateral runoff drainage. 
After considering replenishment and drainage, the water balance equation can be expressed as follows:

$$
\Delta w=\left(q_{p l}+q_{r}+q_{l i}+q_{p}+q_{c}+q_{f}+q_{b}\right)-\left(q_{\varepsilon}+q_{l o}+q_{s}+q_{m}\right)
$$

Where $\Delta w$ denotes the groundwater balance difference; $q_{p l}$ is the piedmont lateral water infiltration amount; $q_{r}$ represents the river infiltration amount; $q_{l i}$ denotes the section lateral inflows; $q_{p}$ denotes the amount of precipitation and condensed water infiltration; $q_{c}$ is the canal water infiltration capacity; $q_{f}$ denotes the field water infiltration capacity; $q_{b}$ denotes the urban and rural industrial water covering groundwater infiltration amount; $q_{\varepsilon}$ stands for the potential water evaporation and plant transpiration; $q_{l o}$ denotes the section lateral outflow, $q_{s}$ denotes the amount of spring water overflow; and $q_{m}$ denotes the artificial exploitation.

\section{The Water Balance Model between Supply and Demand}

According to the principle of water balance and based on the groundwater equilibrium pattern and using the irrigation areas as the unit, the model consisted of a calculation of the discharged flow and analysis of water balance between supply and demand and water shortage in the irrigation areas of the Zhengyixia control cross-section. The principle of the water resources allocation considered the priority of groundwater to supply industrial and domestic water in urban and rural areas and irrigation water with the use of high and new water-saving technologies. Agriculture water and other water utilization in the irrigation areas were supplied by surface water, and the insufficient portion was supplied by groundwater within the limit of groundwater exploitation.

The rationale of the water balance model between supply and demand could be described by the following mathematical model.

Water balance between supply and demand:

$$
\begin{aligned}
& \mathrm{w}_{p}=\mathrm{w}_{s}+\mathrm{w}_{\varepsilon} \\
& \mathrm{w}_{l}=\mathrm{w}_{p}-\mathrm{w}_{n}
\end{aligned}
$$


Balance of surface water:

$$
\begin{gathered}
\mathrm{q}_{s}=\mathrm{a}_{i} \mathrm{gf}_{i} \\
\mathrm{q}_{o}=\mathrm{q}_{i}+\mathrm{q}_{s}-\mathrm{w}_{s}-q_{d}
\end{gathered}
$$

Balance of groundwater:

$$
\begin{gathered}
\mathrm{w}_{r}=\mathrm{q}_{p l}+\mathrm{q}_{r}+\mathrm{q}_{l i}+\mathrm{q}_{p}+\mathrm{q}_{c}+q_{f}+\mathrm{q}_{b} \\
\mathrm{w}_{d}=\mathrm{q}_{\varepsilon}+\mathrm{q}_{l o}+\mathrm{q}_{s}+\mathrm{q}_{m} \\
\Delta w=\mathrm{w}_{r}-\mathrm{w}_{d}
\end{gathered}
$$

Constraint:

$$
\begin{gathered}
\mathrm{w}_{\varepsilon} \leq \mathrm{w}_{\max } \\
\Delta w \leq \beta
\end{gathered}
$$

Where $w_{p}$ denotes the total water supply in the irrigation areas, $w_{s}$ represents the surface water supply in the irrigation areas, $w_{\varepsilon}$ is groundwater exploitation in irrigation areas, $q_{d}$ denotes the channel loss, $w_{l}$ represents the strength of spring overflow, $f_{i}$ denotes the area of spring overflow, $q_{i}$ represents the surface influx in the irrigation areas, $q_{o}$ is the surface outflow in the irrigation areas, $w_{r}$ denotes the groundwater recharge of the boundary in the irrigation areas, $w_{d}$ denotes the groundwater replenishment of the boundary in the irrigation areas, $w_{\max }$ denotes the limitation of groundwater exploitation in the irrigation areas, and $\beta$ denotes the groundwater equilibrium constraints.

\section{Generalization of the Water Resources System in the Heihe River}


The principle of the water resources system generalization utilizes the water distribution unit as the center and the Heihe River as the main line on the basis of the entire basin, different calculation units, administrative regions (inter-provincial and inter-county) and the entrance of the water diversion (combined) of each calculation unit. The water control section was utilized as a water quantity control node. With consideration of the tributaries which have hydraulic connections with the Heihe River surface water, the calculating units were divided according to administrative divisions, which will not break the irrigation divisions.

According to the actual operating conditions and administrative subordination relations, the middle reach based on irrigation area, the lower reach based on the river trend, the scientific research base, the national defense base and the ecological oasis, the calculating units of the water allocation are divided into 24 sections. Based on the needs of the water resources allocation and to reflect the internal relations among each of the main factors that can affect the analysis of supply and demand, the frame of the water resources system in the Heihe River Basin was simplified by calculating the spatial relationship and hydraulic connections among units, surface drainage, groundwater, large or medium-sized and key hydraulic engineering, as shown in Figure 4. 


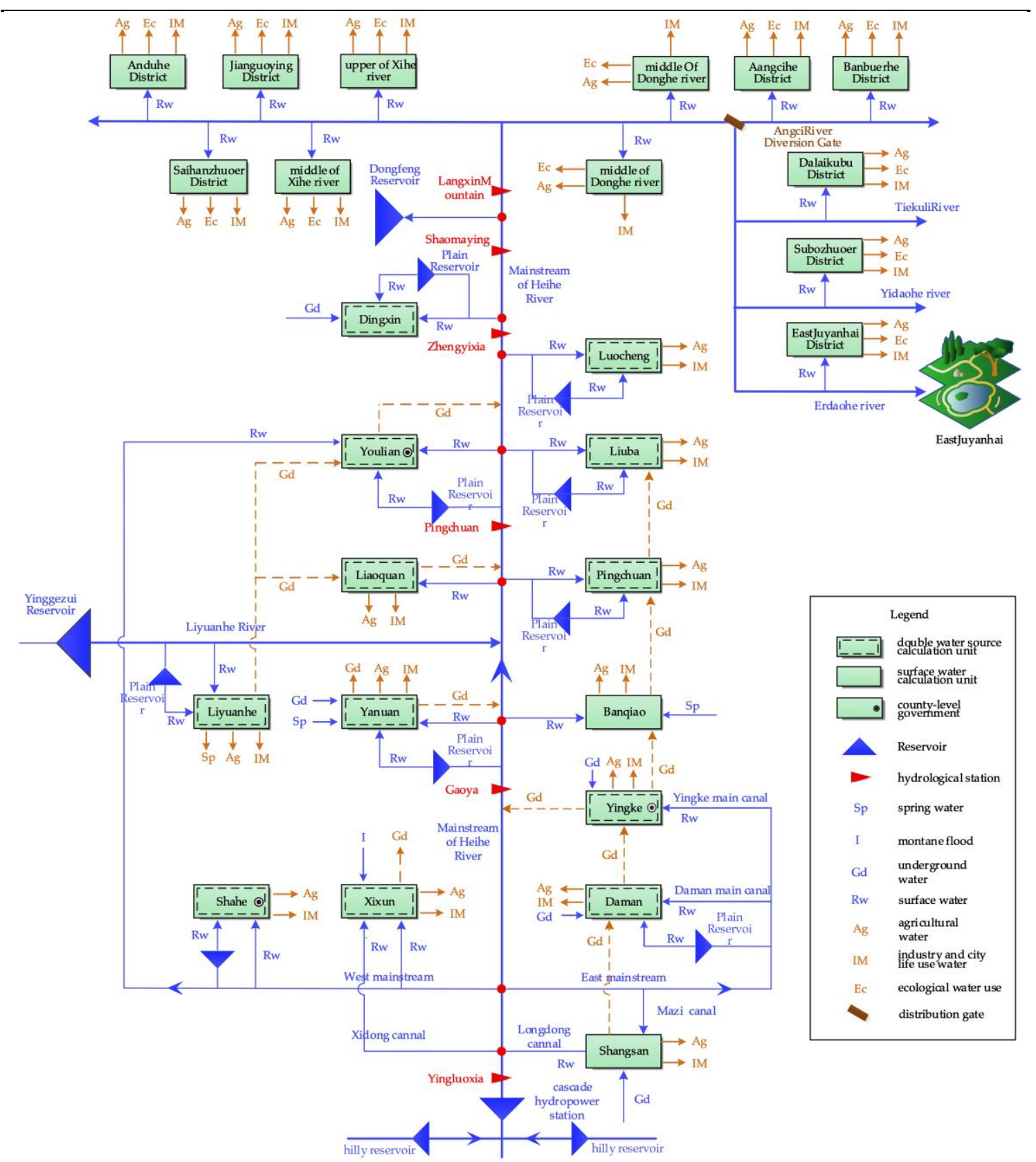

Figure 4. Water resources system frame in Heihe River Basin.

\section{Model Verification}

To examine the rationality of this model, the groundwater level of each irrigation area and the stream flow of each river section for the period from 2005 to 2010 were simulated, and the equilibrium relationships among the groundwater replenishment capacity, total water discharge 
and groundwater storage variable of each irrigation area were analyzed. According to "The Supplementary Details of Groundwater Resources Amount and Allowable Groundwater Withdrawal", the absolute value of the relatively balanced error should be less than $10 \%$ for the computational accuracy of groundwater balance in the flat area. It can be seen from the simulation results that, the model can efficiently fit the water balance in the irrigation area, and the imitative effects of the cross-section streamflow were good.

\section{Simulation Results under the Present Water Demand Condition}

According to the water demand in the middle reaches of the Heihe River in an actual year, the completion of the water division scheme from 1954 to 2012 was obtained by calculating the model. Figure 5 shows the simulation results of water diversion scheme under the present water demand conditions from 1954 to 2012. Table 1 shows the simulation of the releasing indicator under present water demand conditions in different typical years. The irrigation guarantee rate was calculated as flows:

$$
\text { Irrigation guarantee rate }=\frac{n}{N+1}
$$

where $n$ denotes the number of years when the irrigation was satisfied, $N$ means the total years. 


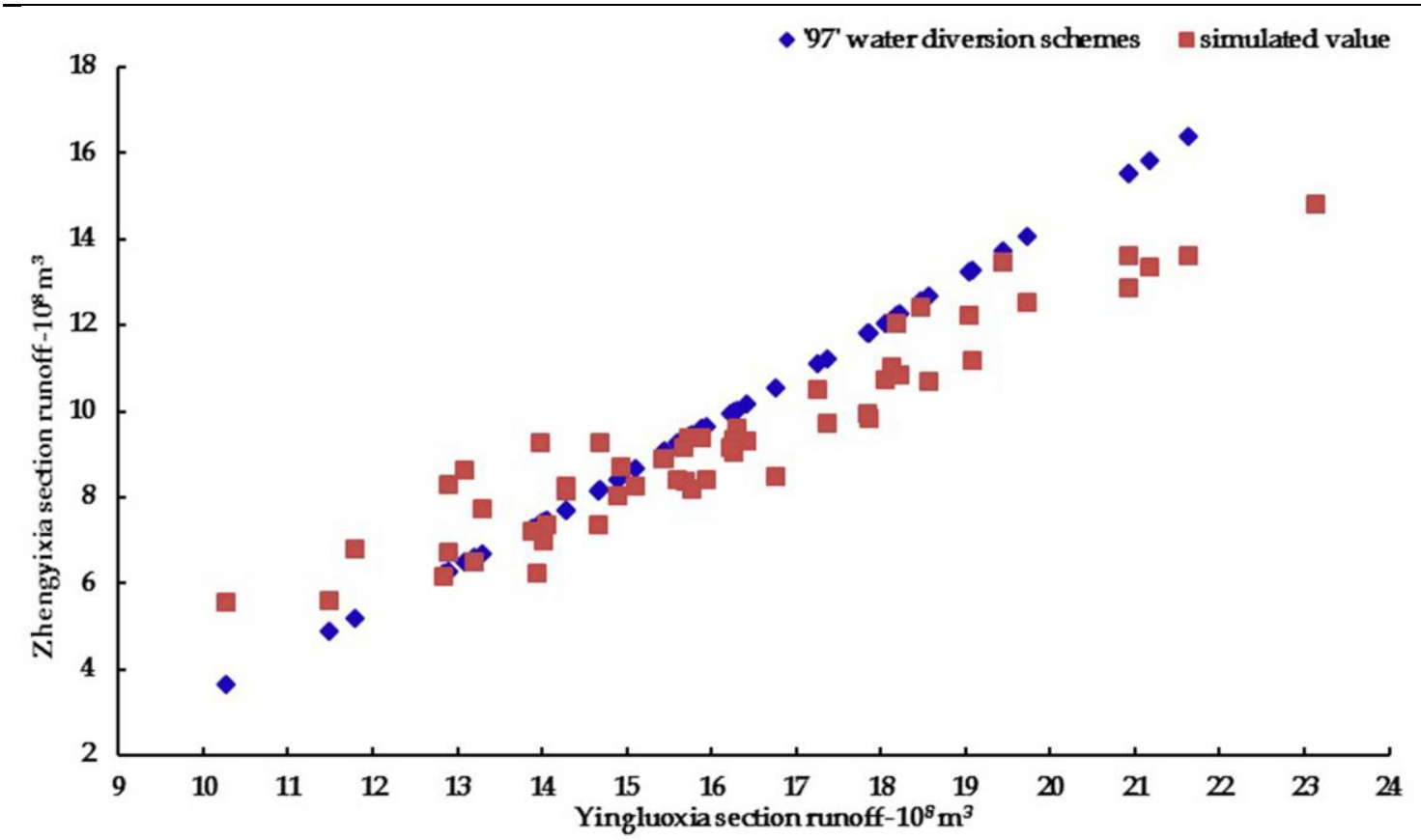

Figure 5. Simulation results of the water diversion scheme under present water demand conditions from 1954-2012.

Table 1. Simulation of the releasing indicator under present water demand in different typical years. Unit: $10^{8} \mathrm{~m}^{3}$.

\begin{tabular}{|c|c|c|c|c|c|c|c|}
\hline \multirow[b]{2}{*}{$\begin{array}{c}\text { Typical } \\
\text { years }\end{array}$} & \multirow[b]{2}{*}{$\begin{array}{c}\text { Yingluoxia } \\
\text { section }\end{array}$} & \multicolumn{3}{|c|}{ Zhengyixia section } & \multirow[b]{2}{*}{$\begin{array}{l}\text { Groundwater } \\
\text { exploitation }\end{array}$} & \multirow[b]{2}{*}{$\begin{array}{c}\text { Irrigation } \\
\text { guarantee } \\
\text { rate }\end{array}$} & \multirow[b]{2}{*}{$\begin{array}{l}\text { Simulated of } \\
\text { Langxinshan } \\
\text { section }\end{array}$} \\
\hline & & \begin{tabular}{|l|} 
Releasing \\
indicator
\end{tabular} & $\begin{array}{l}\text { Simulated } \\
\text { releasing }\end{array}$ & $\begin{array}{c}\text { Water } \\
\text { shortage }\end{array}$ & & & \\
\hline $\begin{array}{c}\text { Extreme } \\
\text { high }\end{array}$ & 20.27 & 14.73 & 13.10 & -1.64 & 6.75 & $0.0 \%$ & 7.05 \\
\hline $\begin{array}{l}\text { Partial } \\
\text { high }\end{array}$ & 17.69 & 11.63 & 10.37 & -1.26 & 6.92 & $0.0 \%$ & 5.45 \\
\hline Normal & 15.63 & 9.29 & 9.22 & -0.07 & 7.30 & $0.0 \%$ & 4.84 \\
\hline $\begin{array}{l}\text { Partial } \\
\text { low }\end{array}$ & 14.56 & 8.10 & 7.80 & -0.30 & 7.54 & $0.0 \%$ & 4.00 \\
\hline $\begin{array}{c}\text { Extreme } \\
\text { low }\end{array}$ & 12.79 & 6.19 & 7.06 & 0.87 & 7.88 & $0.0 \%$ & 3.74 \\
\hline Average & 16.16 & 9.95 & 9.39 & -0.55 & 7.30 & $0.0 \%$ & 4.94 \\
\hline
\end{tabular}

The simulation of releasing water was less than the releasing indicator in the Zhengyixia section in high flow years, and the water volume discharged to the downstream section fell by $1.64 \times 10^{8} \mathrm{~m}^{3}$ in extreme high flow years and $1.26 \times 10^{8} \mathrm{~m}^{3}$ in partial high flow years. The releasing indicator can be completed in normal flow years and partial 
low flow years. The water volume discharged to the downstream section increased by $0.87 \times 10^{8} \mathrm{~m}^{3}$ in extreme low flow years. The average annual water volume discharged to the downstream section fell by $0.55 \times 10^{8} \mathrm{~m}^{3}$, which was more than allowable deviation $\left(0.5 \times 10^{8}\right.$ $\left.\mathrm{m}^{3}\right)$. The average annual groundwater exploitation was $7.3 \times 10^{8} \mathrm{~m}^{3}$, which was far more than allowable groundwater exploitation $\left(4.8 \times 10^{8}\right.$ $\mathrm{m}^{3}$ ). Hence, we can see from the results that, in the current water demand situation, the releasing indicator could not be completed, and long-term overexploitation of groundwater will worsen the ecological environment in the middle reaches.

\section{Simulation Results under the Cultivated Land in the Midstream Decreased}

The main reason that the releasing indicator cannot be achieved in high flow years was the increasing water demand in the midstream. The increase in cultivated land in the midstream was the main driving factor for the increase in water demand, and the reduction in water demand in the midstream was an important approach for reaching the releasing indicator in high flow years under the '97' water diversion scheme. There were two schemes for returning farmland in the midstream to the level in 2000 and to "The Planning of the Heihe River's Government in recent years", which aimed to accordingly calculate agricultural water demand and then simulate the completion of the releasing indicator under two water demand schemes from 1954 to 2012.

Figure 6 illustrates the simulation results of the water diversion scheme from 1954 to 2012 underwater demand level in 2000. Table 2 shows the simulation of the releasing indicator under the 2000 water demand in different typical years. As shown in Table 2, the Zhengyixia section still could not complete the releasing indicator in high flow years, and the water volume discharged to the downstream section decreased by 1.36 $\times 10^{8} \mathrm{~m}^{3}$ in extreme high flow years and $0.95 \times 10^{8} \mathrm{~m}^{3}$ in partial high flow years. The releasing indicator can be completed in normal and low flow years. The average annual water volume discharged to the downstream section fell by $0.33 \times 10^{8} \mathrm{~m}^{3}$, which was less than allowable deviation. The average annual groundwater exploitation was $6.28 \times 10^{8} \mathrm{~m}^{3}$, less than the value under the present water demand condition, while it was still more than allowable groundwater exploitation. 


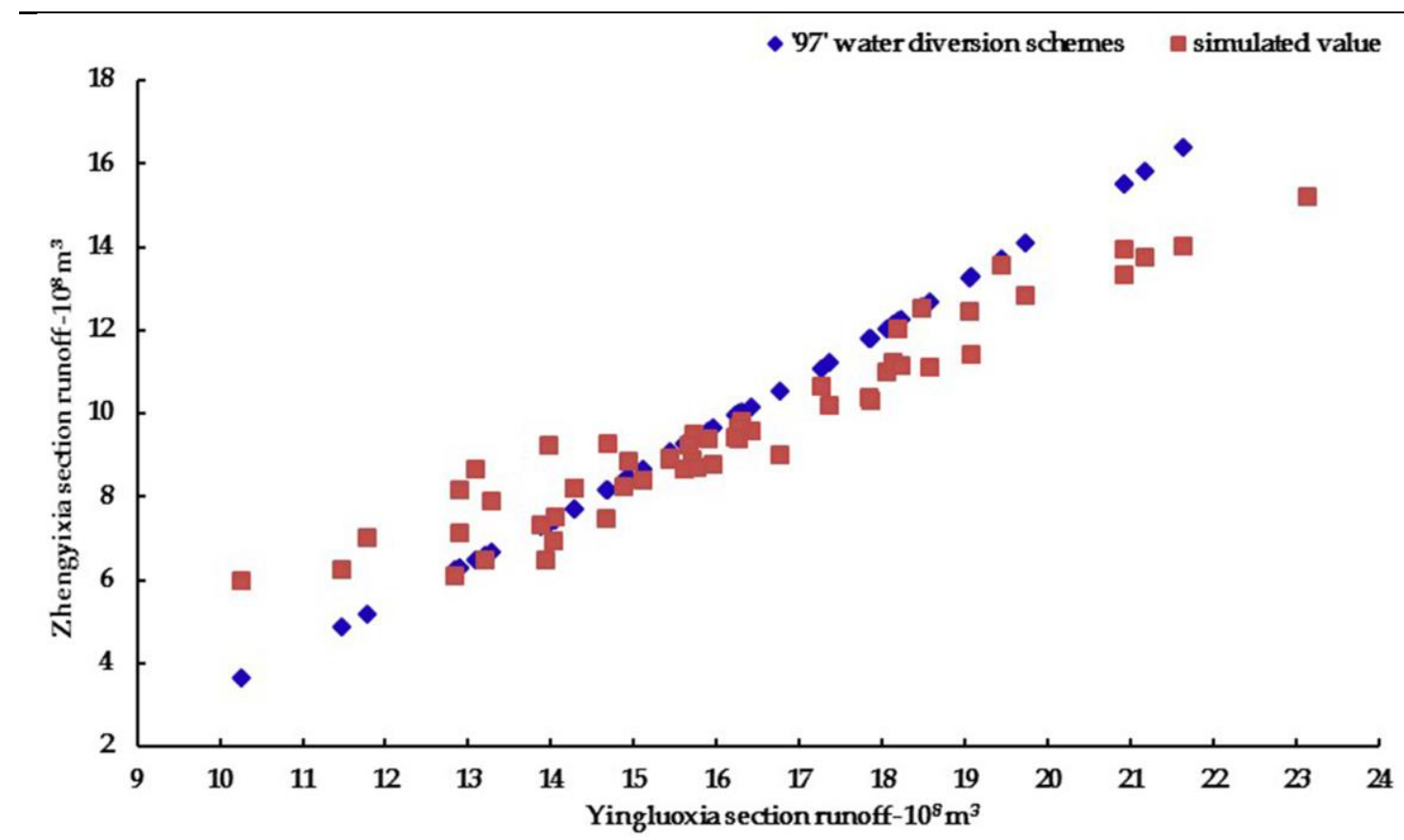

Figure 6. Simulation results of the water diversion scheme from 1954-2012 under the 2000 water demand.

Table 2. Simulation of the releasing indicator under the 2000 water demand in different typical years. Unit: $10^{8} \mathrm{~m}^{3}$.

\begin{tabular}{|c|c|c|c|c|c|c|c|}
\hline \multirow{2}{*}{$\begin{array}{l}\text { Typical } \\
\text { years }\end{array}$} & \multirow{2}{*}{$\begin{array}{c}\text { Yingluoxia } \\
\text { section }\end{array}$} & $\begin{array}{c}\text { Zhengyixia } \\
\text { section }\end{array}$ & $\begin{array}{l}\text { Groundwater } \\
\text { exploitation }\end{array}$ & $\begin{array}{c}\text { Irrigation } \\
\text { guarantee } \\
\text { rate }\end{array}$ & \multirow{2}{*}{$\begin{array}{l}\text { Simulated of } \\
\text { Langxinshan } \\
\text { section }\end{array}$} & & \\
\hline & & $\begin{array}{l}\text { Releasing } \\
\text { indicator }\end{array}$ & $\begin{array}{l}\text { Simulated } \\
\text { releasing }\end{array}$ & $\begin{array}{c}\text { Water } \\
\text { shortage }\end{array}$ & & & \\
\hline $\begin{array}{l}\text { Extreme } \\
\text { high }\end{array}$ & 20.27 & 14.73 & 13.37 & -1.36 & 5.75 & $20.0 \%$ & 7.23 \\
\hline $\begin{array}{l}\text { Partial } \\
\text { high }\end{array}$ & 17.69 & 11.63 & 10.68 & -0.95 & 5.87 & $0.0 \%$ & 5.88 \\
\hline Normal & 15.63 & 9.29 & 9.35 & 0.06 & 6.29 & $11.1 \%$ & 4.91 \\
\hline Partial low & 14.10 & 7.62 & 7.83 & 0.21 & 6.64 & $25.0 \%$ & 4.00 \\
\hline \begin{tabular}{|}
$\begin{array}{c}\text { Extreme } \\
\text { low }\end{array}$ \\
\end{tabular} & 12.79 & 6.19 & 7.23 & 1.04 & 6.80 & $25.0 \%$ & 3.79 \\
\hline Average & 16.16 & 9.95 & 9.62 & -0.33 & 6.28 & $14.5 \%$ & 5.05 \\
\hline
\end{tabular}

Figure 7 illustrates the simulated results of the water diversion scheme from 1954 to 2012 under the recent harnessing plan, and Table 3 shows the simulation of the releasing indicator under the recent harnessing 
plan in different typical years. As displayed in Table 3, the average annual releasing indicator was accomplished when the arable land in the midstream returned farmland to the requirement in the recent harnessing plan underwater demand schemes. However, the water volume discharged to the downstream section fell by $0.61 \times 10^{8} \mathrm{~m}^{3}$ in high flow years, and the water volume discharged to the downstream section increased by $1.4 \times 10^{8} \mathrm{~m}^{3}$ in low flow years. Irrigation guarantee rate in the midstream was nearly $50 \%$. However, the average annual overuse of groundwater in the midstream was nearly 1 $\times 10^{8} \mathrm{~m}^{3}$, whereas there was no extra water to supply groundwater or other environmental water, which might make the environment consistently worse in the midstream.

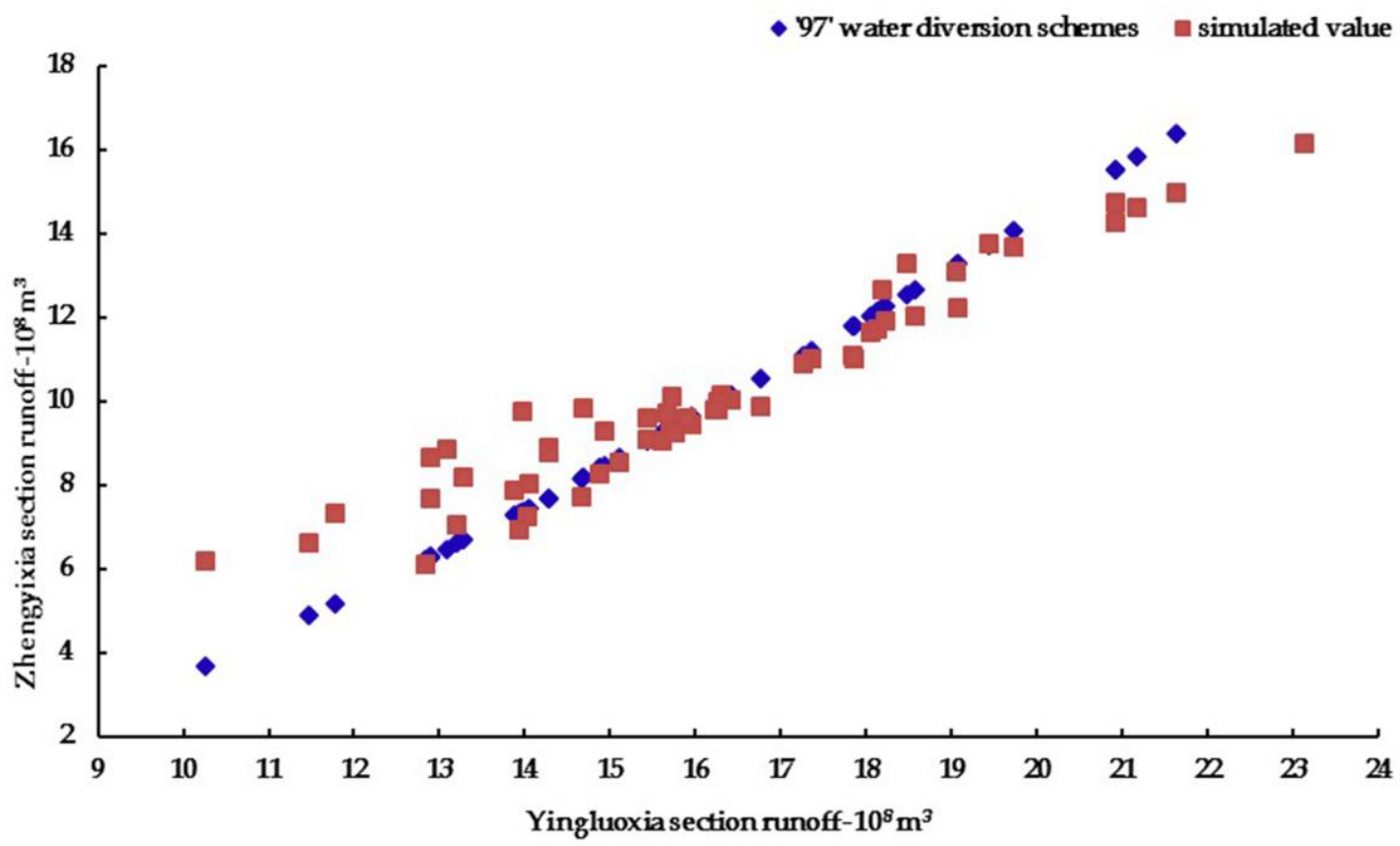

Figure 7. Simulation results of the water diversion scheme from 1954-2012 under the recent harnessing plan.

Table 3. Simulation of the releasing indicator under the recent harnessing plan in different typical years. Unit: $10^{8} \mathrm{~m}^{3}$.

\begin{tabular}{|c|c|c|c|c|c|c|c|}
\hline \multirow[b]{2}{*}{$\begin{array}{c}\text { Typical } \\
\text { years }\end{array}$} & \multirow[b]{2}{*}{$\begin{array}{l}\text { Yingluoxia } \\
\text { section }\end{array}$} & \multicolumn{3}{|c|}{ Zhengyixia section } & \multirow[b]{2}{*}{$\begin{array}{l}\text { Groundwater } \\
\text { exploitation }\end{array}$} & \multirow[b]{2}{*}{$\begin{array}{c}\text { Irrigation } \\
\text { guarantee } \\
\text { rate }\end{array}$} & \multirow[b]{2}{*}{$\begin{array}{c}\text { Simulated of } \\
\text { Langxinshan } \\
\text { section }\end{array}$} \\
\hline & & $\begin{array}{l}\text { Releasing } \\
\text { indicator }\end{array}$ & $\begin{array}{l}\text { Simulated } \\
\text { releasing }\end{array}$ & $\begin{array}{c}\text { Water } \\
\text { shortage }\end{array}$ & & & \\
\hline $\begin{array}{l}\text { Extreme } \\
\text { high }\end{array}$ & 20.27 & 14.73 & 14.12 & -0.61 & 5.32 & $27.3 \%$ & 7.65 \\
\hline
\end{tabular}




\begin{tabular}{|c|c|c|c|c|c|c|c|}
\hline Partial high & 17.69 & 11.63 & 11.30 & -0.33 & 5.41 & $42.9 \%$ & 5.88 \\
\hline Normal & 15.63 & 9.29 & 9.85 & 0.56 & 5.81 & $66.7 \%$ & 5.12 \\
\hline Partial low & 14.10 & 7.62 & 8.25 & 0.63 & 6.13 & $43.8 \%$ & 4.16 \\
\hline $\begin{array}{c}\text { Extreme } \\
\text { low }\end{array}$ & 12.79 & 6.19 & 7.61 & 1.41 & 6.26 & $25.0 \%$ & 3.94 \\
\hline Average & 16.16 & 9.95 & 10.14 & 0.19 & 5.79 & $49.1 \%$ & 5.28 \\
\hline
\end{tabular}

\section{Rationality Analysis of the '97' Water Diversion Scheme}

To sum up, in the current water demand situation, the releasing indicator of the '97' water diversion scheme could not be completed. The water diversion scheme could accomplish the releasing indicator when the farmland in the middle reaches returned to the level in 2000 and the harnessing plan in recent years, but the irrigation guarantee rate in the middle reaches is low and the situations of groundwater overuse are universal, which are caused by the great changes of economic and social conditions, as well as the hydrologic connectivity after the implementation of the water diversion scheme. Therefore, there is some irrationality between the '97' water diversion scheme based on economic, social and hydrologic conditions in the Heihe River in the mid-1980s and the current situation of the Heihe River Basin. Considering the actual need and the water resources status of the Heihe River Basin, it is deeply needed to find a new optimal water diversion scheme which can direct the water resources allocation in Heihe River Basin, and finally achieve the goals that ensure water usage in the middle reaches in low flow years, while allocating more water to the downstream in high flow years.

\section{Potential Measures}

Based on this situation, the potential measures that need to be adopted in the future were: 1) to decrease and control the cultivated land area; 2 ) to implement water saving measures; 3) to decrease and control the volume of groundwater exploitation to ensure an appropriate groundwater level; 4) to optimize the water diversion scheme to meet 
the current situation of the Heihe River Basin; 5) to optimize the water resources allocation process to satisfy the irrigation and ecological water demand in the Heihe River Basin.

\section{Conclusions}

In this study, the water diversion based on the long-term data sets was simulated by the establishment of a water allocation model. In the current water demand situation, the releasing indicator cannot be satisfied in wet years because the economic, social and hydrological conditions have changed greatly before and after the diversion and the '97' water diversion scheme were suitable for the present situation of the Heihe River based on the socio-economic and hydrological conditions of the Heihe River in the mid-1980s.

When reducing the arable land of the middle reaches to the recent management planning requirements, the releasing indicator for the long-term data sets were successfully completed; in addition, the requirements of the water diversion scheme in the different typical years were mainly completed. This result indicates that according to the requirements of "Heihe River Recent Management Plan" to manage the land and water resources of the Heihe River, the '97' water diversion scheme could be achieved, but the irrigation guarantee rate in the middle reaches is low and the situations of groundwater overuse are universal. What's more, the scheme did not consider the environment water demand of the middle reaches, which may cause a deterioration of the environment of the middle reaches.

In summary, due to the environment changes, the '97' water diversion scheme of the Heihe River cannot complete the releasing indicator. There exist some irrationalities in the '97' water diversion scheme based on economic, social and hydrologic conditions in the Heihe River in the mid-1980s and the current situation of the Heihe River Basin. Although the implementation of the ' 97 ' water diversion scheme has effectively improved the utilization efficiency of water resources, ameliorated the environment of the lower reaches, and promoted the economic and social development in the Heihe River Basin, the irrationality of the '97' water diversion scheme under the background of changing environment results in some problems to water resources management in the Heihe River Basin. In order to ensure the sustainable development of regional resources development and utilization and the environment, the '97' water diversion scheme should 
be optimized based on the present condition in the Heihe River, which is very necessary to promote the efficient utilization and scientific management of water resources.

\section{Acknowledgments}

This research was supported by the National Natural Science Foundation of China (grant number 91325201 and 51190093) and the National Department Public Benefit Research Foundation of Ministry of Water Resources (grant number 201501058). We greatly appreciate the professional comments and corrections from the editor and reviewers, which greatly improved the final version of this paper.

\section{References}

Guo, Q., Feng, Q. \& Li, J. (2009). Environmental changes after ecological water conveyance in the lower reaches of Heihe River, northwest China. Environmental Geology, 58(7), 1387-1396.

Huang, S. Z., Huang, Q., Chang, J. X. \& Leng, G. Y. (2016a). Linkages between hydrological drought, climate indices and human activities: a case study in the Columbia River basin. International Journal of Climatology, 36(1), 280-290.

Huang, S. Z., Huang, Q., Leng, G. Y. \& Chang, J. X. (2016b). A hybrid index for characterizing drought based on a nonparametric kernel estimator. Journal of Applied Meteorology and Climatology, 55(6), 1377-1389.

Huang, S. Z., Huang, Q., Leng, G. Y. \& Liu, S. Y. (2016c). A nonparametric multivariate standardized drought index for characterizing socioeconomic drought: A case study in the Heihe River Basin. Journal of Hydrology, 542 875-883.

Jiang, X. H. \& Liu, C. M. (2009). The response of vegetation to water transport in the lower reaches of the Heihe River. Acta Geographica Sinica, 64(7), 791-797.

Kharrazi, A., Akiyama, T., Yu, Y. \& Li, J. (2016). Evaluating the evolution of the Heihe River Basin using the ecological network analysis: Efficiency, resilience, and implications for water resource management policy. Science of the Total Environment, 572, 688-696.

Liu, X. L. \& Wang, L. Z. (2012). Discussion of dispatching schemes and water transfer curves in Heihe River mainstream. Gansu Water Resources and Hydropower Technology, 48(10), 16-18.

Lu, Z. Y., Tang, D. S., Zheng, B. \& Zhu, C. G. (2011). Post-evaluation of the ecological impact of water diversion and recent management in the downstream Heihe River. Acta Scientiae Circumstantiae, 31(7), 


\section{6-1561.}

Tang, D. S. \& Jiang, X. H. (2009). Transferring water and post-assessment of recent controlling in the Heihe River. Beijing: China Water \& Power Press.

Thevs, N., Peng, H. Y., Rozi, A., Zerbe, S. \& Abdusalih, N. (2014). Water allocation and water consumption of irrigated agriculture and natural vegetation in the Aksu-Tarim river basin, Xinjiang, China. Journal of Arid Environments, 112, 87-97.

Wu, B., Zheng, Y. \& Wu, X. (2015). Optimizing water resources management in large river basins with integrated surface water-groundwater modeling: A surrogate-based approach. Water Resources Research, 51(4), 2153-2173.

You, J. J., Wang, H. \& Gan, H. (2006). Current status and prospect of study on simulation model of water resources system. Advances in Water Science, 17(3), 425-429.

Zhang, Y. C., Yu, J. J., Qiao, M. Y. \& Yang, H. W. (2011). Effects of eco-water transfer on changes of vegetation in the lower Heihe River Basin. Shuili Xuebao, 42(7), 757-765.

Zhao, Q. \& Huang, W. D. (2015). Analysis and evaluation on effect of water integrated regulation and comprehensive river basin management of the Heihe River. Yellow River, 37(8), 60-63. 